\title{
Omeprazole enhances efficacy of triple therapy in eradicating Helicobacter pylori
}

\author{
T J Borody, P Andrews, G Fracchia, S Brandl, N P Shortis, H Bae
}

\begin{abstract}
Triple therapy has been recommended as the most effective treatment for Helicobacter pylori eradication. Despite achieving a comparatively high eradication result, however, around $10 \%$ of patients still fail to be cured. Omeprazole can enhance efficacy of single and double antibiotic protocols and is particularly effective when combined with clarithromycin and a nitroimidazole. This study examined the effect of combining triple therapy with omeprazole. A prospective, randomised, unblinded, single centre trial was carried out on consecutive patients with symptoms of dyspepsia and $H$ pylori infection confirmed by rapid urease test, microbiological culture, and histological assessment. Patients were given a five times/day, 12 day course of
\end{abstract} colloidal bismuth subcitrate chewable tablets (108 $\mathrm{mg})$, tetracycline $\mathrm{HCl}$ (250 $\mathrm{mg})$, and metronidazole (200 $\mathrm{mg}$ ) with either $20 \mathrm{mg}$ omeprazole twice daily (triple therapy+omeprazole) or $40 \mathrm{mg}$ famotidine (triple therapy + famotidine) at night. Compliance and side effects were determined using a standard questionnaire form. One hundred and twenty five of 165 triple therapy+omeprazole patients and 124 of 171 triple therapy+famotidine patients returned for rebiopsy four weeks after completion of treatment. Significantly more triple therapy+omeprazole patients achieved eradication 122 of $125(97 \cdot 6 \%)$ as assessed by negative urease test, culture, and histological assessment, when compared with 110 of $124 \quad(89 \%)$ triple therapy +famotidine patients $(p=0.006$; $\left.\chi^{2}\right)$. There were 30 triple therapy+ omeprazole $(24 \%)$ and 26 triple therapy + famotidine $(21 \%)$ patients with de novo metronidazole resistant $H$ pylori included in the study. Side effects were mild and infrequent and were comparable in both groups, although pain in duodenal ulcer, gastric ulcer, and oesophagitis patients seemed to subside earlier in those taking omeprazole. Compliance $(>95 \%$ of drugs taken) was achieved by $98 \%$ of patients of both groups. A 12 day regimen of triple therapy with omeprazole is more effective in achieving $H$ pylori eradication than is triple therapy plus famotidine. Use of $20 \mathrm{mg}$ omeprazole twice daily rather than $40 \mathrm{mg}$ famotidine with a 12 day, low dose triple therapy enhances eradication to over $97 \%$ whether the
$H$ pylori is metronidazole sensitive or resistant.

(Gut 1995; 37: 477 -481)

Keywords: Helicobacter pylori, omeprazole, eradication.

Eradication of Helicobacter pylori is of importance in achieving a cure of duodenal and gastric ulcer disease. However, the ideal therapeutic regimen for its eradication remains elusive. Triple therapy, using bismuth subcitrate, metronidazole, and tetracycline or amoxycillin achieves the highest eradication results ${ }^{1}$ and has therefore been recommended as the preferable treatment for ulcer disease. ${ }^{2}$ Even with this combination of three drugs active against $H$ pylori, around $10 \%$ of patients fail to be cured of the infection. ${ }^{3}$ The reasons for failure are unclear, but compliance and metronidazole resistance are thought to be of importance. ${ }^{3}$

When studying $H$ pylori eradication in patients in whom seemingly adequate treatment with triple therapy had failed to cure the infection, ${ }^{4}$ we found that addition of omeprazole to triple therapy (quadruple therapy) cured overall $78 \%$ of those infected. Furthermore, addition of omeprazole to monotherapy, such as amoxycillin, was known to improve $H$ pylori eradication with success ranging from $30-80 \% .{ }^{5}$ The few studies available on omeprazole combined with dual therapy also suggest eradication enhancement ranging from $43 \%$ to over $90 \% .^{126-10}$ Studies combining omeprazole with triple therapy as first line of treatment have suggested consistently high eradication in excess of $90 \% .^{11} 12$ There has been no formal prospective work, however, to look for any positive contribution that omeprazole might give to the already high eradication rates achieved by triple therapy currently given with $\mathrm{H}_{2}$ receptor antagonists. In this study we examine the effect of adding omeprazole to triple therapy and contrast this with the addition of famotidine to triple therapy, which is used routinely in our standard clinical protocol.

\section{Methods}

Patients

The study was a prospective, randomised, unblinded, single centre trial carried out on patients with dyspepsia referred to the Centre for Digestive Diseases. Dyspepsia symptoms included epigastric pain or discomfort, nausea, vomiting, eructation, bloating or heartburn. Patients were included in the study if $H$ pylori 
eradication was clinically judged to be of benefit to the patient. A proportion of the patients suffering from non-ulcer dyspepsia or oesophagitis in whom other treatments had failed were included in the study as there is preliminary evidence that in subgroups of such categories symptomatic benefit can occur. ${ }^{1314}$ Another significant subgroup of patients had been diagnosed previously as having radiologically or endoscopically confirmed ulcer disease but were currently endoscopically free of ulcers or scarring. All patients gave their informed consent to be included in the study, which was conducted in accordance with the revised Declaration of Helsinki ${ }^{15}$ and was approved by the ethics committee of the Centre for Digestive Diseases. Patients were excluded from the study if they had previously failed any $H$ pylori therapy, on the assumption that they belonged to the 'eradication failure' category. ${ }^{4}$

\section{$\mathrm{H}$ pylori status}

Presence of $H$ pylori infection was assessed endoscopically in every patient by rapid urease test, histological examinations, and microbiological culture of gastric biopsy specimens obtained before the treatment and four weeks after completion of triple therapy. All examinations were performed by the same endoscopist (TJB) with the specimens taken from the gastric antrum and body. The methods used have been described previously ${ }^{1617}$ and will be summarised here. One antral specimen was placed in a microtitre tray, which contained buffered urea and an indicator for rapid detection of urease activity as previously described. ${ }^{18}$ Two antral specimens were taken for microbiological culture, which in our hands is the most sensitive method of detecting the presence of $H$ pylori ${ }^{1617}$ One antral and one gastric body specimen was placed in $10 \%$ buffered formalin for histological examination carried out using a modified Giemsa stain. The results were considered $H$ pylori positive if any one of the three tests used (rapid urease, microbiology or histology) showed evidence of $H$ pylori infection. Metronidazole resistance was determined on chocolate agar by comparative disc diffusion ( $50 \mu \mathrm{g}$ concentration) using NCTC 11639 reference $H$ pylori strain. Resistance was deemed present with a zone of inhibition of less than $5 \mathrm{~mm}$.

\section{Treatment}

Patients were given a triple therapy regimen consisting of chewable colloidal bismuth subcitrate (De Nol; $108 \mathrm{mg}$ ), tetracycline $\mathrm{HCl}$ $(250 \mathrm{mg})$, and metronidazole $(200 \mathrm{mg})$ five times per day ${ }^{20}(7 \mathrm{am}, 11 \mathrm{am}, 3 \mathrm{pm}, 7 \mathrm{pm}$, $11 \mathrm{pm}$ ) for 12 days with either omeprazole $(20 \mathrm{mg})$ at 7 am and $7 \mathrm{pm}$ or famotidine $(40 \mathrm{mg})$ at $11 \mathrm{pm}$ only. The omeprazole dose was chosen to be equivalent to that used in the omeprazole-amoxycillin trials. ${ }^{21}$ The famotidine $40 \mathrm{mg}$ night time dose had replaced ranitidine as our standard $\mathrm{H}_{2}$ receptor antagonist combined with triple therapy. ${ }^{20} \mathrm{At}$ least four weeks after the completion of triple therapy (mean (SD) 33.8 days) patients had another biopsy to assess $H$ pylori eradication. Urease test, histological assessment and culture were again used to detect evidence of $H$ pylori infection.

\section{Compliance and side effects}

To obtain high eradication we endeavoured to maximise patient compliance by educating and training the patients in taking the drugs with which considerable experience had been accumulated at the centre. ${ }^{22}$ Verbal explanations and printed instructions were given to the patient. These emphasised that a totally compliant 'first time therapy' would guarantee a near $100 \%$ cure while retreatment could result in a considerable fall in eradication success. To assess compliance, patients filled out a standard questionnaire and were interviewed at the six week visit. This has been a successful tool in our hands as measured by eradication success. Patients were asked to grade the side effects of nausea, vomiting, abdominal pain, oral discomfort, diarrhoea, constipation, and rash from nil to severe. Scores were assigned according to severity in the following way: nil, score 0 ; no side effects experienced: mild, score 1; effects seen but could be disregarded: moderate score 2 ; effects bad enough to call doctor but could continue treatment and tolerate discomfort: severe, score 3; effects interfered with activities at work; side effects had to be treated or triple therapy had to be discontinued. In practice, a score of 1 was assigned to patients who did not recall side effects when asked 'did you have any side effects?' but who recalled experience of side effects when confronted with a list of individual side effects. A score of 2 or more was given when patients could recall side effects without prompting. For this reason, only scores of 2 or 3 were included as 'clinically significant side effects'.

\section{Statistical analysis}

$H$ pylori eradication for the triple therapy regimens with famotidine and omeprazole was compared using the $\chi^{2}$ test. The differences between mean values of side effects' severity in the two groups and mean number of doses missed by non-compliant patients were determined by Student's $t$ test. All values with $\mathrm{p}<0.05$ were considered to be statistically significant.

\section{Results}

A total of 165 and 171 patients were randomly assigned to the triple therapy plus omeprazole and triple therapy plus famotidine groups respectively. One hundred and twenty five patients returned following the triple therapy+omeprazole regimen $(75 \cdot 8 \%)$ and 124 patients who received triple therapy+famotidine regimen $(72.5 \%)$, four weeks after completion of treatment.

Despite a complete phone follow up and remuneration offer a significant number of 
TABLE I Demographic data of patients included in the study

\begin{tabular}{lcc}
\hline & $\begin{array}{l}\text { Triple therapy } \\
\text { omeprazole }\end{array}$ & $\begin{array}{l}\text { Triple therapy+ } \\
\text { famotidine }\end{array}$ \\
\hline Number & 125 & 124 \\
Mean age (SD) & $51 \cdot 4(12 \cdot 8)$ & $52 \cdot 5(15 \cdot 5)$ \\
Male/female & $60 / 65$ & $67 / 57$ \\
Eradication of H pylori $(\%)$ & $122 / 125(97 \cdot 6)$ & $110 / 124(89)$ \\
Diagnosis & 38 & 34 \\
Duodenal ulcer & 5 & 3 \\
Gastric ulcer & 50 & 37 \\
Non-ulcer dyspepsia & 22 & 23 \\
Oesophagitis & 21 \\
Other (past history of ulcer) & 11 & \\
\hline
\end{tabular}

Some patients had multiple diagnoses.

patients could not be induced to undergo the second endoscopy, often for a variety of economic reasons including preservation of employment status. In addition, as in our previous studies, most ( $64 \%$ of those contacted) claimed they were feeling well and did not wish to proceed with the re-endoscopy. Symptomatic patients were more interested to see whether they still carried the infection ${ }^{20} 23$ and returned more frequently for rebiopsy. The bias in the study was therefore towards the $H$ pylori positive patients returning with a presumed equivalent 'loss to follow up' occurring in each of the study arms.

Of the patients who returned for reendoscopy 111 in the triple therapy+ omeprazole group and 103 in the triple therapy + famotidine group filled out side effect questionnaire forms. Demographic data and predominant endoscopic diagnosis for all patients included in the analysis of the study was listed. There were no significant demographic or diagnostic differences between the groups of patients using triple therapy with either omeprazole or famotidine (Table I).

\section{$\mathrm{H}$ pylori eradication}

$H$ pylori was judged to be eradicated in 122 of $125(97 \cdot 6 \%)$ patients using the triple therapy+omeprazole regimen. Conversely, 110 of $124(89 \%)$ patients were cured of $H$ pylori using triple therapy+famotidine regimen. All three tests used, urease, histological assessment, and microbiology, had to be negative to consider $H$ pylori as being eradicated. There was a significant statistical difference found between these eradication results $\left(p=0.006 ; \chi^{2}\right)$. The initial sample (165 triple therapy+omeprazole and 171 triple therapy+famotidine patients) would have provided more than $80 \%$ power (the usual value used) to the study but the drop out rate was higher than expected so that in the end the power was $70 \%$. Statistically significant

TABLE II Comparison of side effects between triple therapy plus omeprazole $(T T+O)$ and triple therapy plus famotidine $(T T+F)$, either as scores or absolute values

\begin{tabular}{|c|c|c|c|c|c|c|}
\hline \multirow[b]{2}{*}{ Symptoms } & \multicolumn{2}{|c|}{ Mean (SEM) score } & \multirow[b]{2}{*}{ p Value } & \multicolumn{2}{|c|}{$\begin{array}{l}\text { Clinically significant } \\
\text { side effects }(\%)\end{array}$} & \multirow[b]{2}{*}{$p$ Value } \\
\hline & $T T+O$ & $T T+F$ & & $T T+O$ & $T T+F$ & \\
\hline Nausea & $0.36(0.07)$ & $0.42(0.06)$ & 0.5 & $7 \cdot 2$ & $12 \cdot 6$ & $0 \cdot 18$ \\
\hline Vomiting & $0.07(0.04)$ & $0.07(0.03)$ & 1 & $1 \cdot 8$ & 1.9 & 0.94 \\
\hline Abdominal pain & $0.25(0.05)$ & $0.21(0.04)$ & 0.54 & $2 \cdot 7$ & 1.9 & 0.71 \\
\hline Oral discomfort & $0.24(0.06)$ & $0.25(0.05)$ & 0.9 & $5 \cdot 4$ & $6 \cdot 8$ & 0.67 \\
\hline Diarrhoea & $0.13(0.04)$ & $0.13(0.04)$ & $0 \cdot 87$ & $1 \cdot 8$ & 1.9 & 0.94 \\
\hline Constipation & $0.06(0.03)$ & $0.05(0.02)$ & 0.78 & 0.9 & 0.9 & 0.96 \\
\hline
\end{tabular}

results were found, however, and there was a $70 \%$ chance of finding them if they were present.

\section{Side effects}

Severity of side effects experienced by the patients in the two groups was compared. Table II lists the frequencies of side effects with the most frequent being nausea, occurring in $7 \cdot 2 \%$ (triple therapy +omeprazole) and $12.6 \%$ (triple therapy + famotidine) patients followed by oral discomfort in $5.4 \%$ and $6.8 \%$, presumed to be caused by transient oral candidiasis. Patient compliance did not seem to be affected by these usually minor side effects. Furthermore, there was no statistically significant difference in scores for nausea, vomiting, abdominal pain, oral discomfort, diarrhoea or constipation between the two groups. Although not measured by the questionnaire, there was a distinct clinical impression that dyspeptic symptoms, especially abdominal pain, abated more rapidly in patients using omeprazole.

\section{Compliance}

Based on self reporting, $97 \%$ of patients in the triple therapy+omeprazole group and $96 \%$ of those treated with triple therapy+famotidine were ' $100 \%$ compliant' with the treatment. There was no statistical difference between the two results $(p=0 \cdot 628)$.

\section{Metronidazole resistance}

De novo metronidazole resistance was found to be present in $24 \%$ of patients in the triple therapy +omeprazole and $21 \%$ triple therapy+ famotidine groups. Using the culture methodology described and particularly that of placing gastric biopsy specimens directly onto the culture plate from the biopsy forceps, $H$ pylori growth was obtained in all patients studied. Although it is recognised that in many centres $H$ pylori culture is achieved in no more than $80 \%$ of instances as it was in the early days in our laboratory, our current success rate in over 8000 patients approaches $98 \% .{ }^{17}$ Of the three patients who failed to eradicate $H$ pylori in the triple therapy + omeprazole group one of three was metronidazole resistant, another had recently (within the past four weeks) taken a course of amoxycillin, while the last was incompletely compliant to the treatment.

\section{Discussion}

This study describes the use of triple therapy combined with omeprazole for 12 days. When used in compliant Australian patients this protocol approaches $100 \%(97 \cdot 6 \%)$ eradication. Other clinicians have reported such a combination to be highly efficacious. Hosking et $a l^{11}$ in Hong Kong, using only $20 \mathrm{mg}$ omeprazole in the morning together with colloidal bismuth subcitrate, tetracycline $500 \mathrm{mg}$, and metronidazole $400 \mathrm{mg}$ four times daily $(\mathrm{n}=78)$ achieved eradication in $95 \%$ of patients using 
only a seven day course. This group subsequently published another, similar study, which resulted in $98 \%$ eradication. ${ }^{24}$ In Australia, with a smaller patient group $(n=25)$, Daskalopoulos et al ${ }^{12}$ used a 14 day course of omeprazole $20 \mathrm{mg} /$ day with colloidal bismuth subcitrate, tetracycline $250 \mathrm{mg}$, and metronidazole $200 \mathrm{mg}$ four times daily, achieving $96 \%$ (24 of 25 ) eradication. Such results corroborate our $97 \cdot 6 \%$ result carried out in a large patient cohort, using lower treatment doses. Our patients took $750 \mathrm{mg}$ less tetracycline and $600 \mathrm{mg}$ less metronidazole per day though omeprazole was $20 \mathrm{mg}$ twice daily $v 20 \mathrm{mg} / \mathrm{d}$. A further finding of this study is the higher $H$ pylori eradication by triple therapy achieved by substituting $40 \mathrm{mg}$ omeprazole for $40 \mathrm{mg}$ famotidine. This finding suggests that omeprazole indeed contributes to the improvement in eradication.

Although this protocol may seem cumbersome it works well in clinical practice perhaps because it is brief. Furthermore it is feasible to combine the three components of triple therapy into a fixed dose combination therapy as a single tablet. This would simplify dosing and enhance compliance. In view of the $95 \%$ eradication obtained by Hosking et al ${ }^{11}$ using a seven day protocol it seems probable that a single tablet could be given for only seven days without significant loss of efficacy and perhaps with further reduction in component doses of triple therapy. Indeed, a one day triple therapy (CBS $240 \mathrm{mg} \times 4$; amoxycillin $2 \mathrm{~g} \times 4$; metronidazole $500 \mathrm{mg} \times 4$ ) with $40 \mathrm{mg}$ omeprazole, has achieved an eradication of $72 \%$. ${ }^{25}$ Therefore, there seems to be scope for the reduction not only of triple therapy component doses but also for the reduction in treatment duration.

The use of a simplified protocol using omeprazole and amoxycillin has recently attracted much interest. Variable and often conflicting eradication results have emerged, however, ranging from $28-82 \%$. This led Collins et $a l^{5}$ to conclude that based on present evidence, omeprazole and amoxycillin cannot yet be considered the optimal regimen for eradicating $H$ pylori'. The best of the latest published protocols using the dual therapy achieves an $80-82 \%$ eradication in a population selected out for penicillin sensitive patients. ${ }^{2326}$ This selection further reduces the eradication to $<80 \%$ when considering 'all comers'. The major restriction of amoxycillin containing eradication therapies is the existence of penicillin sensitivity in a significant proportion of the population, which will prevent eradication ever approaching 100\% described here. Tetracycline containing triple therapy does not suffer from this disadvantage and is therefore amenable to further optimisation.

Side effects of triple therapy have been used as an argument to develop alternative protocols. ${ }^{26}$ Side effects of triple therapy are generally minor, however, ${ }^{26-28}$ reduced by the lower dose triple therapy recently introduced, ${ }^{20}$ and clinically have been found to be no different by some to side effects of omeprazole alone. ${ }^{11}$ In this study the combination of five times/day triple therapy with omeprazole resulted in infrequent, mild, and certainly clinically insignificant level of adverse reactions. Though not measured directly, it was our impression that the addition of omeprazole shortened duration of dyspeptic symptoms in those patients with ulcers and reflux symptoms.

In vitro metronidazole resistance of $H$ pylori is currently being invoked as perhaps the major obstacle to more successful eradication when using triple therapy. ${ }^{5272930}$ Metronidazole resistance therapeutic studies, however, have yet to differentiate between patients with de novo and post therapy metronidazole resistance. ${ }^{28} 31$ Indeed, when compliant patient populations with and without de novo metronidazole resistant bacteria are compared, $H$ pylori eradication with triple therapy is virtually equivalent. ${ }^{19}$ On the other hand, there is general agreement that after failed antibiotic treatment $H$ pylori becomes less responsive to re-treatment and even complex antibiotic combinations achieve but modest eradication results ${ }^{63233}$ suggesting that prior, recent exposure to antibiotic treatment or to omeprazole, ${ }^{34}$ may be the major cause of subsequent eradication failure. In fact in vitro 'metronidazole resistance' can develop without metronidazole use ${ }^{35}$ and rather than achieving high eradication, metronidazole free triple therapy (bismuth subcitrate, amoxycillin, tetracycline) has achieved a mere $20 \%$ success. ${ }^{36}$ It is therefore of clinical importance that addition of twice daily omeprazole to triple therapy can virtually remove the perceived problem of metronidazole resistance. With a de novo, in vitro resistance status of $24 \%$ in our triple therapy +omeprazole group and $H$ pylori eradication rates of $97.6 \%$ metronidazole resistance seems to be of no clinical relevance. Such also were the findings of Hosking et al $\mathrm{al}^{24}$ who achieved $98 \%$ eradication in his group of patients despite $48 \%$ metronidazole resistance.

In conclusion, a 12 day course of lower dose five times/day triple therapy combined with 20 mg twice daily omeprazole seems to be an efficient protocol achieving, in unselected patients, an eradication of $H$ pylori of $97.6 \%$ whether it be resistant de novo to metronidazole or not. The high eradication may permit further reduction of triple therapy component dose and a shorter duration of treatment without loss of efficacy.

1 Chiba N, Rao BV, Rademaker JW, Hunt RH. Meta-analysis of the efficacy of antibiotic therapy in eradicating Helicobacter pylori. Am $\mathcal{f}$ Gastroenterol 1992; 87: 1716-27.

2 Axon ATR. Helicobacter pylori therapy: effect on peptic ulcer disease. F Gastroenterol Hepatol 1991; 6: 131-7.

ulcer disease. $\mathcal{F}$ Gastroenterol Hepatol 1991 ; 6: $131-7$.

Ruaws EAJ. Reasons for failure of Helicobacter pylori treat1993; 5 (suppl 2): S92-5.

4 Borody TJ, Brandl S, Andrews P, Jankiewicz E, Ostapowicz $\mathrm{N}$. H pylori eradication failure $(\mathrm{EF})$ - further treatment $\mathrm{N}$. H pylori eradication failure (EF) - furth
possibilities. Gastroenterology 1992; 102: A43.

5 Collins R, Beattie S, Xia HX, O'Morain C. Short report: high-dose omeprazole and amoxycillin in the treatment of high-dose omeprazole and amoxycillin in the treatment of Helicobacter pylori-associated
Pharmacol Ther 1993; 7: 313-5.

6 Al-Assi MT, Genta RM, Graham DY. Failure of omeprazole to enhance antimicrobial therapy for $\mathrm{H}$ pylori omeprazole with tetracycline or tetracycline and bismuth. Am $\mathcal{f}$ Gastroenterol 1993; 88: 1502. 
7 McCarthy CJ, Collins R, Beattie S, Hamilton H, O'Morain C. Short report: treatment of Helicobacter pylori-associated duodenal ulcer with omeprazole plus antibiotics. Aliment Pharmacol Ther 1993; 7: 463-6.

8 Bell GD, Powell KU, Burridge SM, Rameh B, Bolton G, Purser K, et al. Helicobacter pylori eradication: a combination of omeprazole, amoxycillin and metronidazole compared with standard triple therapy. Gut 1993; 34 (suppl 1): S37.

9 Moayyedi P, Axon ATR. Efficacy of a new one week triple therapy regime in eradicating Helicobacter pylori. Gut 1994; 35 (suppl 2): S62.

10 Bazzoli F, Zagary RM, Fossi S, Pozzato P, Roda A, Roda E. Efficacy and tolerability of short term low-dose triple therapy for eradication of Helicobacter pylori. Gastroenterology 1993; 104: A40.

11 Hosking SW, Ling TKW, Yung MY, Cheng A, Chung SCS, Leung JWC, et al. Randomised controlled trial of short term treatment to eradicate Helicobacter pylori in short term treatment to eradicate Helicobacter pylo
patients with duodenal ulcer. $B M F$ 1992; 305: 502-4

12 Daskalopoulos G, Carrick J, Lian R, Lee A. Optimising therapy for $\mathrm{H}$ pylori gastritis. Ir $\mathcal{F}$ Med Sci 1992; 166 (suppl 10): 16

13 Borody T, Andrews P, Brandl S, Macauley D, Hyland L. Does $H$ pylori (HP) play a role in esophageal reflux? Gastroenterology 1993; 104: A44.

14 O'Morain C. Helicobacter pylori and non-ulcer dyspepsia. Gastroenterology 1992; 103: 340-7.

15 World Medical Assembly. The Declaration of Helsinki. World Med $¥ 1982$; 29: 86-8.

16 Borody TJ, George LL, Brandl S, Andrews P, Ostapowicz $\mathrm{N}$, Hyland L, et al. Helicobacter pylori-negative duodenal ulcer. Am 7 Gastroenterol 1991; 89: 1154-7.

17 Borody TJ, Andrews PJ, Brandl S, Hyland L, Morgan A, Ostapowicz N, et al. Endoscopic diagnosis of Helicobacter pylori (H pylori) - approaching the 'Gold Standard' pylori (H pylori) - approaching the 'Gold Standard'.
Abstracts of the World Congresses of Gastroenterology, Sydney, 1990. Abingdon: The Medicine Group (UK) Ltd, 1990: PD91.

18 Hazell SL, Borody TJ, Gal A, Lee A. Campylobacter pylori gastritis. I: Detection of urease as a marker of bacteria colonisation and gastritis. Am $\mathcal{F}$ Gastroenterol 1987; 82: 292-6.

19 Borody T, Andrews P, Brandl S, Devine M. Relevance of in-vitro metronidazole resistance to $H$ pylori (HP) eradication and eradication failure. Gastroenterology 1993; 104: A44.

20 Borody TJ, Brandl S, Andrews P, Ferch N, Jankiewicz E, Hyland L. Use of high efficacy, lower dose triple therapy Hyland $\mathrm{L}$. Use of high efficacy, lower dose triple therapy to reduce side effects of eradicatin

21 Labenz J, Gyenes E, Ruhl GH, Borsch G. Omeprazole plus amoxycillin: efficacy of various treatment regimens to eradicate Helicobacter pylori. Am $\mathcal{f}$ Gastroenterol 1993 88: 491-5.
22 Borody TJ. Possibilities for Helicobacter pylori suppression/eradication. European fournal of Gastroenterology and Hepatology 1992; 4 (suppl 2): S37-40.

23 Borody TJ, Andrews P, Mancuso N, Macauley D, Jankiewicz E, Ferch N, et al. Helicobacter pylori reinfection rate, in patients with cured duodenal ulcer. $A m \mathcal{F}$ Gastroenterol 1994; 89: 529-32.

24 Hosking SW, Ling TKW, Chung SCS, Yung MY, Cheng $\mathrm{AFB}$, Sung JJS, et al. Duodenal ulcer healing by eradication of Helicobacter pylori without anti-acid treatment: randomised controlled trial. Lancet 1994; 343: 508-10.

25 Tucci A, Corinaldesi R, Stanghellini V, Paparo GF, Gasperoni S, Biasco G, et al. One-day therapy for treatment of Helicobacter pylori infection. Dig Dis Sci 1993; 38: $1670-3$.

26 Labenz J, Gyenes E, Ruhl GH, Borsch G. Amoxycillin plus omeprazole versus triple therapy for eradication of Helicobacter pylori in duodenal ulcer disease: a prospective, randomised, and controlled study. Gut 1993; 34: tive, random $1167-70$.

27 Thijs JC, Van Zwet AA, Oey HB. Efficacy and side effects of a triple drug regimen for the eradication of Helicobacter pylori. Scand $\mathcal{F}$ Gastroenterol 1993; 28: 934-8.

28 Burette A, Glupczynski Y, De Prex C. Evaluation of various multi-drug eradication regimens for Helicobacter pylori. Eur $\mathcal{F}$ Gastroenterol Hepatol 1992; 4: 817-23.

29 Tytgat GNJ, Noach LA, Rauws EAJ. Helicobacter pylori. Eur f Gastroenterol Hepatol 1992; 4 (suppl 1): S7-15.

30 Bell GD, Powell K, Burridge SM, Harrison G, Weil J, Gan PW, et al. Does a previous course of tripotassium dicitrato bismuthate affect the subsequent changes of successful Helicobacter pylori eradication? Aliment Pharmacol Ther 1992; 6: 327-33.

31 Xia $H$, Daw MA, Sant $S$, Beattie $S$, Keane CT, O'Morain CA. Clinical efficacy of triple therapy in Helicobacter pAlori-associated duodenal ulcer. Eur $\mathcal{7}$ Gastroenterol Hepatol 1993; 5: 141-4.

32 Marshall BJ, Guerrant RL, Hoffman SR, Barrett RW McCallum RW. Eradication of metronidazole resistant $\mathrm{H}$ pylori [Abstract]. Am f Gastroenterol 1991; 86: 1315.

33 Seppala K, Sipponen P, Farkkila M, Kosunen TU. Quadruple therapy eradicates nitroimidazole resistant $\mathrm{H}$ pylori. Acta Gastroenterolog Belg 1993; 56: 66.

34 Labenz J, Gyenes E, Ruhl H, Borsch G. Pretreatment with omeprazole endangers the effiency amoxicillin/omeprazole treatment to eradicate HP. Ir $\mathcal{F}$ Med Sci 1992; 161 (suppl 10): 12.

35 Daskalopoulos G, Carrick J, Lian RX, Lee A. The silent minority - eradication of Helicobacter pylori infection where standard triple therapy has failed. H pylori. Basic where standard triple therapy has failed. H pylori. Basic mitz-Cariton Hotel, Amelia IS FL; Nov 3-6, 1993: 36.

36 Graham DY, Lew GM, Klein PD, Genta RM, Evans DG. A new triple therapy without metronidazole for Helicobacter pylori infection. Gastroenterology 1992; 102: A76. 